\title{
Changes in the input-output structures of the six regions of Fukushima, Japan: 3 years after the disaster
}

Kiyoshi Yonemoto*

*Correspondence:

yonemoto@tcue.ac.jp

Takasaki City University

of Economics, Takasaki, Japan

\begin{abstract}
This study investigates the changes in input-output and trade structures within the six regions of the Fukushima prefecture in the aftermath of the 2011 Tohoku earthquake, tsunami, and accident at the Fukushima Daiichi Nuclear Power Station, Japan. The model is based on the 2005 multiregional input-output tables of Fukushima prefecture and its extended version, constructed by Yonemoto and Kanno (Innovation I-0 Tech 20: 11-23, 2012). Using more recent data, trade coefficients (intra-prefectural) and import coefficients (inter-prefectural) are modified. A sensitivity analysis, which quantifies the changes in backward-linkage effects, is then performed. The results show that the ripple effect, which decreased across many sectors and regions following the disaster (primarily due to the increase in import rates), has since returned to normal and in some cases has even improved beyond pre-disaster levels. However, in regions which suffered severe devastation, the effects on several sectors such as "Agriculture, Forestry and Fishery" are small and there are indications that those sectors have benefitted less from reconstruction.
\end{abstract}

\section{Background}

The purpose of this study is to characterize the changes in backward-linkage effects within the six regions of the Fukushima prefecture during the 3 years following the 2011 Tohoku earthquake. In order to achieve this, first, the outputs and final demands were estimated for each sector and region using actual data. Then, taking into account these estimated figures, the trade and import coefficients of the input-output tables (multiregional tables for the six regions of the prefecture) were modified. Finally, using these new tables, changes in backward-linkage effects were quantified.

The Tohoku earthquake took place on March 11, 2011. The greater part of the resulting physical damage occurred within three prefectures of the Tohoku region: Iwate, Miyagi, and Fukushima (see Fig. 1). In addition to the direct effects of the earthquake and tsunami, Fukushima suffered a consequent nuclear accident.

For the first few weeks (or months in some cases) after the disaster, the economic difficulties were largely associated with broken supply chains and logistical constraints. Moreover, even after some temporary reconstruction was undertaken, local industries were still faced with another problem: reduced demand. To characterize the situation

(c) 2016 Yonemoto. This article is distributed under the terms of the Creative Commons Attribution 4.0 International License (http:// creativecommons.org/licenses/by/4.0/, which permits unrestricted use, distribution, and reproduction in any medium, provided you give appropriate credit to the original author(s) and the source, provide a link to the Creative Commons license, and indicate if changes were made. 


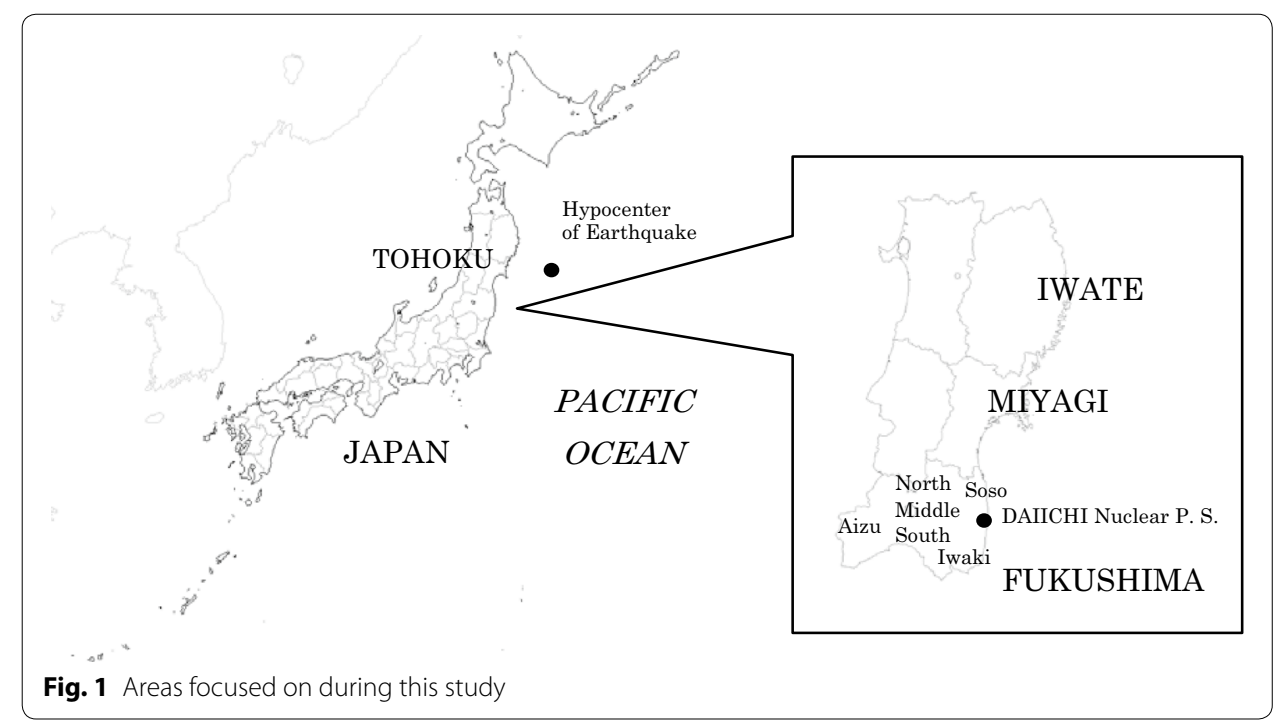

in which demand switches from one region to another for geographical, psychological, structural, or other reasons, Yonemoto and Kanno (2012) modified the trade coefficients (intra-prefectural) and import coefficients (inter-prefectural) of multiregional inputoutput tables and conducted a sensitivity analysis. They made a significant discovery: Because the analysis only used the data released just after the disaster, large changes in the origins of imports were observed in many sectors. In particular, backward-linkage effects were considerably lower in "Agriculture, Forestry and Fishery," "Manufacturing," and "Services" within the coastal regions. Yonemoto and Kanno (2012) then used 2011 data and focused on only two coastal regions among the six regions of the Fukushima prefecture. This study updates and extends this earlier study with new data from 2012 and 2013 in order to continue to examine the trend in the 3 years following the disaster.

There have been many economic studies undertaken on the effect of natural disasters. Others that have used similar input-output analyses include Cochrane (1974), which predicts losses due to a hypothetical earthquake in the vicinity of San Francisco, and Rose et al. (1997), who study the effect of a hypothetical earthquake occurring close to Memphis. Takahashi et al. (1997) combine an input-output analysis with an econometric model and estimate economic losses due to the Great Hanshin earthquake, an earthquake that occurred in Japan in 1995. Okuyama (2004) further analyzes the same earthquake using a "Sequential Interindustry Model." Tsuchiya et al. (2005) examine the economic effect of 2004 Chuetsu Earthquake with a Spatial Computable General Equilibrium (SCGE) model and Yamano et al. (2007) attempt the same using a regional grid model.

Following the 2011 Tohoku earthquake, Chujo et al. (2013) analyzed broken supply chains in the aftermath of the earthquake. Ihara et al. (2013) characterized current economic potentials and then predicted future migration using a spatial framework. Hayashiyama et al. (2014) explored redistributive effects of investment for reconstruction over prefectures.

Other studies using input-output analyses, in particular, the Hypothetical Extraction Method (HEM), which modifies the input coefficients or other coefficients in order 
to characterize the importance of an industry or a region, follow the work of Strassart (1968) and are summarized by Miller and Lahr (2001). Among them is Regional Extraction Model, which was introduced by Dietzenbacher et al. (1993) and extracts a region instead of a sector. Nozaki $(2013,2015)$ in addition has attempted to characterize the impact of 2011 Tohoku earthquake on other regions as well as those directly affected by the shockwaves.

The technique used in this study, along with that of Yonemoto and Kanno (2012), is similar to HEM. In most cases, HEM extracts, based on assumptions but not on actual data, the entire section or region of interest from the economy and then measures its overall significance. However, this study also carefully estimates the changes in trade and import coefficients using actual data and investigates current backward-linkage effects in order to identify the sector or region suffering the greatest hardship. ${ }^{1}$

As far as the author is concerned, one of the main problems with the research that has been conducted so far regarding the aftermath of 2011 earthquake, particularly that related to Fukushima, is that it focuses very little on the actual condition of the residents or firms located in the region. While some people enjoy the benefits the recent demand for reconstruction, others still require urgent aid or even relocation. This study hopes to precisely characterize the economy in these locations and perform practical analysis using these and other observations.

The remainder of this paper is organized as follows: Sect. 2 describes the method of analysis; Sect. 3 summarizes the data used in this study, outlines the pre-disaster economies of the regions on which this study focuses and illustrates the changes in output since the disaster. Section 4 presents the results of these analyses and Sect. 5 concludes.

\section{Methods of analysis}

This section summarizes the primary method of analysis. It is essentially similar to that used by Yonemoto and Kanno (2012).

\subsection{Constructing the multiregional input-output table}

2005 Fukushima Regional IO Table includes data on the aggregate export and import of each region but does not include information on inter-regional trades among the 6 regions of the prefecture. Thus, these are estimated using the following method and a Chenery-Moses multiregional input-output table is constructed. ${ }^{2}$

Following Miyazawa (2005), output balance is described as

$$
x=T A x+T f_{D}+e-m,
$$

\footnotetext{
${ }^{1}$ Most studies and reports, such as Cabinet Office (2012) and Tokunaga et al. (2013), conclude that physical disruptions to the supply chain (e.g., disconnected transportation or destroyed facilities) were restored in several months in most cases. However, in reality, business structure (e.g., trade pattern) has not returned to its original state for years in some industries. This study, which concentrates on the current situation, mainly models the latter and derives ordinary backward-linkage effects using the modified coefficients. Note that, as Chujo et al. (2013) summarize, some studies (e.g., the ones that use the Ghosh model) characterize the forward-linkage effect (shock to the supply chain) just after the disaster by reducing the output of the corresponding region exogenously while keeping the coefficients constant. This study begins by changing the coefficients, similar to the HEM method, and then derives the outputs.

2 Since the table includes information on the export and import of each region, it is not necessary to estimate the trades from the beginning. (Otherwise, more general methods such as non-survey methods by Miyagi et al. (2003), Okamoto et al. (2005), and Asari and Doi (2008) need to be used). In other words, this study partially "recovers" and then enhances the work of those who created the 2005 Fukushima Regional IO Table.
} 
where $x$ is the $(N R \times 1)$ vector of outputs, in which $N=13$ and $R=6$, the numbers of the sectors and regions, respectively, $e$ is the inter-prefectural and international export, $m$ is the inter-prefectural and international import, and $f_{D}$ is the final demand except the export and import. $A$ is the input coefficient matrix and $T$ is the matrix of trade coefficients among six regions:

$$
\begin{gathered}
A \equiv\left(\begin{array}{cccc}
A^{1} & 0 & \cdots & 0 \\
0 & A^{2} & \cdots & 0 \\
\vdots & \vdots & \ddots & \vdots \\
0 & 0 & \cdots & A^{R}
\end{array}\right), \quad A^{r} \equiv\left(\begin{array}{cccc}
a_{11}^{r} & a_{12}^{r} & \cdots & a_{1 N}^{r} \\
a_{21}^{r} & a_{22}^{r} & \cdots & a_{2 N}^{r} \\
\vdots & \vdots & \ddots & \vdots \\
a_{N 1}^{r} & a_{N 2}^{r} & \cdots & a_{N N}^{r}
\end{array}\right) \\
T \equiv\left(\begin{array}{cccc}
T^{11} & T^{12} & \cdots & T^{1 R} \\
T^{21} & T^{22} & \cdots & T^{2 R} \\
\vdots & \vdots & \ddots & \vdots \\
T^{R 1} & T^{R 2} & \cdots & T^{R R}
\end{array}\right), \quad T^{r s} \equiv\left(\begin{array}{cccc}
t_{1}^{r s} & 0 & \cdots & 0 \\
0 & t_{2}^{r s} & \cdots & 0 \\
\vdots & \vdots & \ddots & \vdots \\
0 & 0 & \cdots & t_{N}^{r s}
\end{array}\right)
\end{gathered}
$$

2005 Fukushima Regional IO Table indicates the amounts of input and output within each region:

$$
\hat{T} A x+\hat{T} f_{D},
$$

where $\hat{T} \equiv\left(\begin{array}{cccc}T^{11} & 0 & \cdots & 0 \\ 0 & T^{22} & \cdots & 0 \\ \vdots & \vdots & \ddots & \vdots \\ 0 & 0 & \cdots & T^{R R}\end{array}\right)$.

It also indicates the aggregate export (the sum of intra-prefectural, inter-prefectural, and international exports) of each region, which is,

$$
e_{R E G}=e_{I N T R A}+e,
$$

where $e_{I N T R A} \equiv(T-\hat{T}) A x+(T-\hat{T}) f_{D}$.

Moreover, it indicates the aggregate import,

$$
m_{R E G}=m_{I N T R A}+m,
$$

where $m_{R E G}=\operatorname{diag}(A x) \hat{T}^{\prime}(1, \cdots, 1)^{\prime}+m$.

In order to complete the multiregional table, the first term in the right-hand side of (2.3) or (2.4) needs to be estimated and, in addition, the destinations of export should be identified. That is, the following matrix, which characterizes the amounts of intraprefectural trades, should be constructed for each sector:

$$
\left(\begin{array}{cccc}
0 & e_{I N T R A}^{n 12} & \cdots & e_{I N T R A}^{n 1 R} \\
e_{I N T R A}^{n 21} & 0 & \cdots & e_{I N T R A}^{n 2 R} \\
\vdots & \vdots & \ddots & \vdots \\
e_{I N T R A}^{n R 1} & e_{I N T R A}^{n R 2} & \cdots & 0
\end{array}\right) .
$$


Note that the horizontal sum of its elements is equal to each element of the vector $e_{\text {INTRA. }}$

1. For each sector, using 2005 Fukushima Regional IO Table, calculate the aggregate $e_{\text {INTRA }}^{n r}=\sum_{s=1}^{R} e_{I N T R A}^{n r s}$.

imports (including the ones from the other regions in the prefecture) within the six regions and subtract prefectural imports (not including the trades in the prefecture) from the data contained in the 2005 Fukushima Prefecture Input-Output Table. The difference is regarded as the total amount of intra-prefectural trades:

$\sum_{r=1}^{R} m_{I N T R A}^{n r}\left(=\sum_{r=1}^{R} e_{I N T R A}^{n r}\right)=\sum_{r=1}^{R} m_{R E G}^{n r}-\sum_{r=1}^{R} m^{n r}$.

2. Allocate the total amount to trade flows among regions according to the following gravity ${ }^{3}$ :

$\frac{e_{R E G}^{n r} \times m_{R E G}^{n s}}{d_{r s}}$

To calculate the distance, the location of the city hall in the most populated city of each region is used.

3. If any of the intra-prefectural export or import flow are calculated to be larger than the actual amount (i.e., $e_{I N T R A}^{n r}>e_{R E G}^{n r}$ or $m_{I N T R A}^{n r}>e_{R E G}^{n r}$ ), a simple product model (without distance) will be used instead:

$e_{R E G}^{n r} \times m_{R E G}^{n s}$.

In this study, "mining," "electricity, gas and water supply," "finance and insurance," "real estate", and "information and communications" correspond to these headings.

4. If any intra-prefectural export or import flow remains larger than the actual flow even when the model of 3) is used, starting from the values of 3 ), the weights are iteratively calculated under the constraints of zero diagonal elements to obtain the actual export and import shares of the regions. ${ }^{4}$ In this study, "information and communications" corresponds to this situation.

\subsection{Modifying trade and import coefficients}

Some of the coefficients are modified in order to take into account the effect of the disaster on trade structure.

In (2.1), $\mathrm{M}$ is endogenized as follows:

$$
m=M\left(\hat{T} A x+\hat{T} f_{D}\right)
$$

\footnotetext{
${ }^{3}$ Some studies, such as Nakano and Nishimura (2007), have used gravity to estimate the trades among regions.

4 This iteration is required in some cases because the diagonal elements are constrained to be zero. Otherwise, the method of 3 ) is always valid.
} 
where $M$ is the import coefficient matrix. Solving (2.1) for $x$, output is derived as follows:

$$
x=[I-(T-M \hat{T}) A]^{-1}\left[(T-M \hat{T}) f_{D}+e\right] .
$$

Coefficients are modified as follows: (1) collect information on the change in the output, (2) assume the rate of the change in export (intra-prefectural, inter-prefectural, or international) is equal to the one in output and then recalculate the trade coefficients, (3) final demand is modified according to the information on population after the earthquake, ${ }^{5}$ and (4) define (inter-prefectural and international) imports as the residuals of (1-3), then recalculate the import coefficients. Input coefficients are not modified in this study.

The output balance after the change is described as follows ${ }^{6}$ :

$$
\tilde{x}=\tilde{T} A \tilde{x}+\tilde{T} \tilde{f}_{D}+\tilde{e}-\tilde{M}\left(\tilde{\hat{T}} A \tilde{x}+\tilde{\hat{T}} \tilde{f}_{D}\right) .
$$

Specify $\tilde{T}, \tilde{x}, \tilde{f}_{D}$, $\tilde{e}$ and $\tilde{\hat{T}}$, and derive $\tilde{M}$. Once the coefficient matrices are modified, an input-output analysis is carried out. For given $f_{D}$ and $e$, output is calculated by

$$
x=[I-(\tilde{T}-\tilde{M} \tilde{\hat{T}}) A]^{-1}\left[(\tilde{T}-\tilde{M} \tilde{\hat{T}}) f_{D}+e\right] .
$$

\section{Estimating the changes in outputs}

This section describes the data source, outlines the economy of each region, and estimates the change in output, due to the disaster. Please note that the purpose of this study is not to estimate those outputs accurately but to illustrate the overall input-output and trade structures. Because of the limitations of the immediate data, some figures are estimated using conventional methods. (For more "accurate" figures, please be aware that the reader will need to wait for an official release.)

\subsection{The data}

This study draws data from the "2005 Input-Output Tables for Living Spheres of Fukushima Prefecture," (referred to as 2005 Fukushima Regional IO Table, hereafter), in Fukushima Prefecture (2011). It covers six regions (or "living spheres,") which are "North," "Middle," "South," "Aizu," "Soso," and "Iwaki" (see Fig. 1 for generalized locations). In addition to the 2005 Fukushima Regional IO Table, data from the "2005 Fukushima Prefecture Input-Output Table," Fukushima Prefecture (2010), are used. This is a single-region table, but contains more accurate data (indeed, the 2005 Fukushima Regional IO Table is based on it) and has information on inter-prefectural exports and imports, which can be used to distinguish intra-prefectural exports (imports) from inter-prefectural exports (imports).

\footnotetext{
${ }^{5}$ For more careful modeling of the relationship between the employment and final demand, see Van Dijk and Oosterhaven (1985), for example.

${ }^{6}$ Because all of the post-disaster changes are at first expressed in terms of the (monetary) amounts, not coefficients, and then all coefficients are recalculated, the input and output are always balanced. Moreover, the modified model characterizes the current situation so that it is not possible to compare its predicted values with realized ones (at least for now). Therefore, this study does not indicate a statistical proof of the model. However, it might be included in future extensions.
} 
The entire research is based on the simplest 13-sector system of tables, because while there are also tables available containing data for 36 sectors and 91 (or 107) sectors, the current information regarding damage caused by the earthquake is not detailed enough to allow for greater complexity.

The 2005 Fukushima Regional IO Table provides inverse matrices in addition to basic input-output matrices. However, this study uses new inverse matrices that are consistent with the trade and import coefficients derived from analysis.

Other data on the changes in outputs and populations are obtained from various sources. Details are described in the corresponding sections.

\subsection{Characteristics of economies of the six regions}

The six regions within the prefecture, North, Middle, South, Aizu, Soso, and Iwaki, had different economic structures even before the earthquake. They are outlined as follows.

Soso is a region whose population density is relatively low and houses Fukushima Daiichi (No. 1) and Daini (No. 2) Nuclear Power Stations as well as several thermal power stations. The production from the corresponding sector as of 2007 accounted for $56 \%$ of the total production of the region. After the nuclear accident, more than half of the area of the Soso region was either evacuated (mostly within $20 \mathrm{~km}$ from the Daiichi Station) or had some restriction on activities imposed (mostly within $30 \mathrm{~km}$ ).

Iwaki is relatively industrialized and the manufacturing sector accounts for $44 \%$ of its total production. Exports as well as imports of the sector are high so the region is considered to be specialized in processing trade. Other sectors with high (regional) demands include Construction, Commerce, Real Estate, Public Administration, and Services. Iwaki contains the sea port of Onahama, one of the largest industrial and fishing ports in Japan.

North (Ken-poku), Middle (Ken-chu), and South (Ken-nan) are located along a major highway (the Tohoku Expressway) and Railroad (the Tohoku Shinkansen). They were not damaged by the tsunami but have been affected by the nuclear accident to some extent. Aizu is in the west and so was the least affected by the earthquake, tsunami, or nuclear accident.

Fukushima City, the prefectural capital is located in the North. The economic structure is similar to that of Iwaki. When comparing both, the North can be seen to have higher imports in Manufacturing and higher production in Public Administration.

Middle is a relatively urbanized region and contains populated cities such as Koriyama and Sukagawa. The economic structure is similar to that of Iwaki and North. The only significant difference is its export of Information and Communications.

The size of the economy of South is almost a half of that of Iwaki, North, or Middle. It differs from them in its lower level of commerce and services.

Aizu is the region developed in the Aizu Basin. Again, the size of the economy is almost a half that of Iwaki, North, or Middle. It has relatively higher exports in "Agriculture, Forestry and Fisheries," some export in "Electricity, Gas and Water Supply," higher shares in "Construction," "Public Administration," and "Services," and lower exports in "Manufacturing."

Using the methods described in Sect. 2 for estimating the trades among the six regions, Yonemoto and Kanno (2012) constructed a regional input-output table of the 
Chenery-Moses type. The table revealed a large number of exports from Middle in major sectors such as "Manufacturing," "Commerce," "Transportation," "Information and Communications," and "Services." Furthermore, trades of "Agriculture, Forestry and Fishery" products among North, Middle, South, and Aizu in particular stand out. Other prominent trades include exports from the "Mining" sectors (Iwaki to Soso), and "Electricity, Gas and Water Supply" from Soso to the other regions and "Finance and Insurance" from North, where the prefectural capital is located.

\subsection{Estimated changes in agriculture, forestry, and fishery}

\subsubsection{Agriculture}

Crop Statics from the Ministry of Agriculture, Forestry and Fisheries (MAFF) are released annually and include data on rice production at municipal level. Because rice is a major agricultural product in most of the locations studied and no detailed data are available for the other agricultural products, this study assumes that the rate of the change in rice production represents the same rate for the complete agricultural production in each region. ${ }^{7}$

The decline in the amount of (prefectural) rice production was, when compared to $2010,20.7,17.2$, and $14.1 \%$ in 2011,2012 , and 2013, respectively. The decline is in most instances due to changes in output in the Soso region, the region which was most severely damaged by the tsunami and the nuclear accident.

\subsubsection{Forestry}

Municipal- or regional-level data on forestry production are not frequently released. Therefore, it is approximated as follows 8 :

$$
z_{t}^{i}=x_{t}^{1 i} \times \frac{\sum_{i \in I} z_{t}^{i}}{\sum_{i \in I} z_{2010}^{i}} \times \frac{\sum_{i \in I} x_{2010}^{1 i}}{\sum_{i \in I} x_{t}^{1 i}}
$$

where $z_{t}^{i}$ and $x_{t}^{1 i}$ are forestry and agricultural (rice) productions in city (town or village) $i$ in period $t$, respectively. $I$ is the set of cities, towns, and villages of Fukushima prefecture.

The data on forestry production are based on Statistics on Forestry Production Income, provided by MAFF. Prefectural production was 8.72 billion yen $(69.7 \%$ of the total of 2010), 7.39 billion yen (59.2\%), and 7.67 billion yen (61.4 \%) in 2011, 2012 and 2013 , respectively. Using the rates, the amounts of forestry production are estimated at municipality level.

\subsubsection{Fisheries}

According to data from the Fukushima Prefecture (2013), the output of coastal fisheries decreased from 9.2 billion yen in 2010 to 1.3 billion in 2011 (a decrease of $85.9 \%$ ). As of 2013, the situation remains unchanged since coastal fishing is forbidden or self-regulated for many species. However, some Fukushima-based vessels are now operating in

\footnotetext{
7 This study assumes no changes in price. The price of other products, such as fruits, may have decreased much so that the actual value of the entire production can be lower than the estimation of this study.

8 Yonemoto (2013) used the data on aggregate agricultural production by Fukushima Prefecture (2013), instead of the ones on rice production, to estimate 2011 values, which are also used in this study. Because of data availability, 2012 and 2013 values are based on rice production.
} 
other areas and their outputs are therefore included. As a result, according to Annual Statistics of Fisheries and Fish Culture from MAFF, the output of sea fisheries decreased from 18.2 billion yen in 2010 to 8.7 billion (a decrease of $52.3 \%$ ) in 2011 and 6.4 billion (a decrease of $64.8 \%$ ) in $2012 .{ }^{9}$ The total (prefectural) output is distributed among municipal or regional levels by weight-based data taken from Annual Statistics.

For fresh-water fisheries and fish culture, only weight-based data are available even at the prefectural level. The output of fresh-water fisheries decreased from 372 tons in 2010 to 27 tons in 2011 (92.7 \% decline) and 22 tons in 2012 (a decrease of 94.1\%). Also, the output of fresh-water culture decreased from 1615 tons in 2010 to 1181 tons in 2011 (a $27 \%$ decline) and 1119 tons in 2012 (a decrease of $30.7 \%$ ). The weight is converted to monetary units by species, using national-level value data. Monetary values were estimated to be 111 million, 36.2 million (decreased by $67.3 \%$ ), and 29.8 million (73.1\%) in 2010, 2011, and 2012, respectively, for fresh-water fisheries. The figures for freshwater culture are 819 million, 616 million (a decrease of $24.8 \%$ ) and 577 million (29.5\%). Because no municipal- or regional-level data are available, the same rates are used for all inland cities, towns, and villages.

\subsubsection{Unifying agriculture, forestry, and fishery}

So far, monetary values have not been explicitly calculated for agriculture and forestry. City, Town, and Village Accounts from the Fukushima Prefecture are the only data source that describes monetary values by sub-sector and municipality. Since these data indicate only the value-added amounts, they are converted to the values of outputs, dividing by the value-added ratios, using data from the 2005 Fukushima Regional IO Table. With respect to the fishery outputs, as the 2013 values are currently not available, they are assumed to have remained static since 2012.

Figure 2 summarizes the estimated changes in the values of outputs. Note that the values for 2011(*), which are calculated using the rates estimated in Yonemoto and Kanno (2012), are presented for reference purposes only. ${ }^{10}$ The declines in the value of the "Agriculture, Forestry and Fishery" output from the prefecture are estimated to be 24.3, 24.6, and $21.1 \%$ for 2011, 2012, and 2013, respectively. The declines in Soso region are $87.8,87.9$, and $83.7 \%$, respectively.

\subsection{Construction}

Housing Starts (construction of new houses) statistics from the Civil Engineering Department, Fukushima Prefecture are the only available municipal-level monthly data associated with construction. These data are assumed to represent the changes in the entire industry. Housing Starts fell just after the disaster, returned to their original level around August 2011 and a housing boom began in October 2012. In contrast to the other prefectures hit by tsunami, Fukushima's reconstruction was delayed by about a year.

\footnotetext{
9 This study does not take into account sea culture because data are not available: The value of its output was 533 million in 2010. It declined in 2011 and only a few enterprises were actually operating. As a result, the data were concealed by statistical disclosure law.

10 The rates were estimated just after the disaster, using the relationship between the value of an agricultural product and the radiation level, and intended to characterize the changes in the values of the entire agricultural production. Because later studies assume no changes in prices of the agricultural products, 2011 (without an asterisk) productions are estimated to be much larger than those of 2011(*) in regions other than Soso.
} 


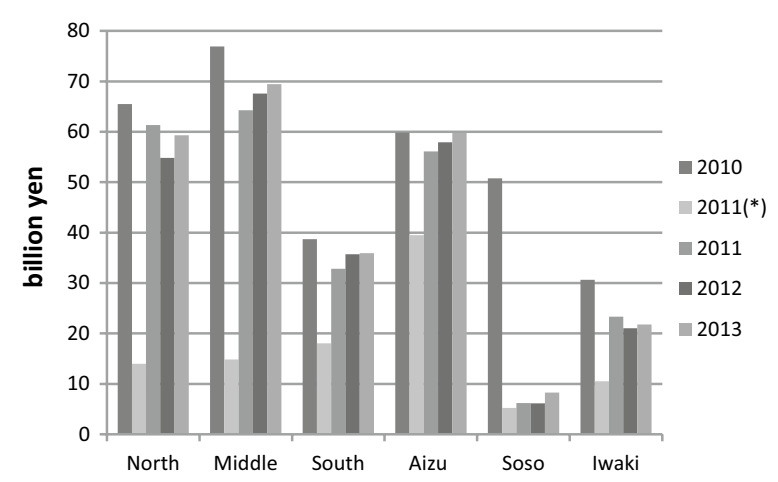

Fig. 2 Agriculture, Forestry, and Fishery Outputs (Estimated). Asterisk The amounts of $2011^{*}$ ) are the ones used in Yonemoto and Kanno (2012)

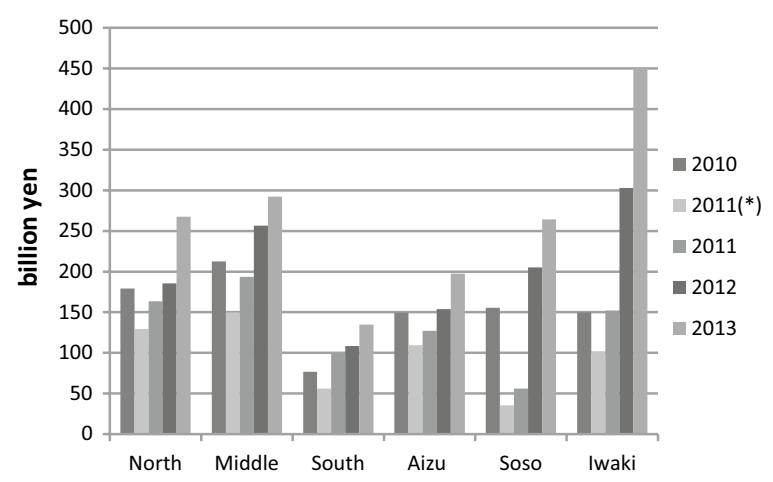

Fig. 3 Construction (estimated)

Based on the data, the values for the output of the construction sector can be estimated (see Fig. 3). ${ }^{11}$ The initial negative shock was the largest in the Soso region (64\% decline). A sharp increase then followed in Soso and Iwaki regions. It can be noted in contrast, that construction (in terms of value-added) in the case of Great Hanshin Earthquake 1995 doubled in just a few months but in this case, the speed of reconstruction was much slower.

\subsection{Public administration}

Due to the nuclear accident, most of the town and village offices in the Soso region were moved to other regions. After 3 years, some have returned to their original places or nearby locations. Table 1 summarizes the movement of these offices.

This study assumes public service is (produced and) provided in a region where the (head) office is currently located. ${ }^{12}$ As a result, regional outputs of public administration

\footnotetext{
${ }^{11}$ Because full monthly data are available, taking into account the date of the disaster, housing starts in a period from March in the year to February in the next year is used to represent the total number of each year.

12 The assumption was largely consistent with the actual situation (total evacuation) in 2011. In later years, as some returns have been admitted and the citizens are divided into evacuees and those who have returned, public services are also dispersed. Moreover, the amount of public expenditure may have changed because of demographic change, additional governmental aid, etc. A better way of estimation should be developed to take into account them.
} 
Table 1 Moves of town and village offices of Soso region (as of 2013)

\begin{tabular}{ll}
\hline Municipality & Temporary location (Region, as defined by this study) \\
\hline litate Village $^{a}$ & Fukushima City (North) \\
Katsurao Village $^{a}$ & Miharu Town (Middle) \\
Namie Town $^{\text {a }}$ & Nihonmatsu City (North) \\
Futaba Town $^{\text {b }}$ & Iwaki City (Iwaki) \\
Okuma Town $^{c}$ & Aizu-Wakamatsu City (Aizu) \\
Kawauchi Village $^{d}$ & Returned to the original place (Soso) \\
Tomioka Town $_{\text {Naraha Town }}$ & Koriyama City (Middle) \\
Hirono Town $^{d}$ & Iwaki City (Iwaki) \\
\hline Proparned to the original place (Soso)
\end{tabular}

a Preparing for partial return

b Once evacuated to Kazo City (Saitama Prefecture)

c Also have branches in Iwaki City (Iwaki) and Nihonmatsu City (Middle)

d Once evacuated to Koriyama City (Middle)

e Once evacuated to Aizu-Misato City (Aizu)

for 2013 have increased by 4.5, 4.3, 3.5, and 7.8 \% in "North," "Middle," "Aizu," and "Iwaki" (no change in "South,") and decreased by 37.9 \% in "Soso."

\subsection{Electricity, gas, and water supply}

As has been noted in earlier sections, as of 2005, the output of the "Electricity, Gas and Water Supply" sector accounts for about $56 \%$ of total production for the Soso region. Since the disaster, all thermal power stations have been restored. ${ }^{13}$ However, it has proved difficult to restore and restart the two nuclear stations previously operating in this region. As a result, the capacity of electricity generation is less than half of the predisaster level (34.3\% as of 2012 and $49.7 \%$ as of April 2013).

In the Iwaki region, since an old (thermal power) unit was renewed in 2012 and a new (coal) unit was added in 2013, production (capacity) has actually increased by $17 \%$. As for the Gas and Water Supply, which account for only $1.4 \%$ of the output of the Soso region, adjustments are made based on the output shares from municipalities, assuming the values to be zero for evacuated towns and villages. The outputs for the regions other than Soso and Iwaki are kept constant.

\subsection{Manufacturing and mining}

The outputs of Manufacturing and Mining are estimated based on the Indices of Industrial Production (by prefecture) supplied by the Ministry of Economy, Trade and Industry (METI). These dipped just after the disaster but rose again in the following months. Since the end of 2011, the figures for manufacturing have been slightly depressed when compared to pre-disaster ones, while the figures for mining have been slightly elevated.

Because these indices only include the prefecture, using Active and New Job Opening data provided by the Fukushima Labour Bureau for the Ministry of Health, Labour and Welfare (MHLW), regional adjustments are calculated as follows:

${ }^{13}$ Haramachi thermal station, which had been the last station under restoration, restarted its operation on March 29, 2013. Thus, as of April 2013, all thermal stations of Soso region are operating. 
1. Estimate the relationship between New Job Openings (\% change) and Output (\% change) by section.

2. Assume the ratio between New Job Openings and Active Job Openings is constant. Then, the (\%) difference in Active Job Openings among regions is also equal to that in New Job Openings (Note that regional-level data are released only for Active Job Openings.)

3. Using the relationship estimated in 1) and the value derived in 2), the difference in outputs among regions is calculated.

In most regions, New Job Openings (sum of the all sections) have increased since the disaster.

According to these estimations, the outputs of the Manufacturing industry of South have increased (by 28 \% between 2010 and 2013), while those of North, Middle, and Aizu have decreased (by 19, 14, and $7 \%$, respectively). In the case of Mining, the outputs of South and Soso have increased, while those of the other regions fell at first and then rose again.

\subsection{Other industries}

For the remaining six industries, because official data are released so infrequently, it is extremely difficult to estimate outputs accurately. The only available data are for Active and New Job Openings, which have already been mentioned in the above section. Since there are no prefectural-level data on output that corresponds to the Indices of Industrial Production in the last subsection, their changes are also represented by those of New Job Openings (at prefectural level).

\subsection{Populations and final demands}

For the populations of the regions, the figures given for March 1, 2011, 2012, and 2013, showing the Estimated Population of the Fukushima Prefecture, are compared to each other. $^{14}$ The prefectural population (based on resident registration) has decreased rapidly (approximately $4.3 \%$ ) in the 3 years following the disaster. In particular, Soso has recorded a $8.2 \%$ decline in population in 3 years.

\section{Analysis}

Based on the outputs and final demands estimated in Sect. 3, trade coefficients (intraprefectural) and import coefficients (inter-prefectural) are modified using the methods described in Sect. 2.

This section investigates the properties of the modified multiregional input-output tables and analyzes the effect of an increase in final demand on the outputs. Section 4.1 summarizes the changes in import coefficients. Section 4.2 describes the change in the effect of an increase in demand for each sector on the entire prefectural economy. (That is, it indicates which sector should be supported in order to obtain the greatest economic ripple effect in total). Sections 4.3 and 4.4 characterize the effect of growth on

\footnotetext{
${ }^{14}$ Actually, the number of the evacuees is much larger than that of migrants based on resident registration. Refer to Yonemoto (2012) for details of migration. This study intends to use "official" figures as long as they are available. Thus, simple population data (based on resident registration) are used.
} 
the entire economy in each sector (This enables us to identify which sector or region has benefited most from economic recovery in general.)

\subsection{Changes in import coefficients}

Under the remit of this study, import coefficients have the most essential role in characterizing the changes in economic structure following the disaster. In particular, their increase (due to difficulties in obtaining domestic goods, for example) reduces the ripple effects and may delay the economic recovery of a region.

Import coefficients are recalculated using the method described in Sect. 2.2, taking into account the outputs and final demands estimated in the previous section. The rates have increased in the sectors of "Agriculture, Forestry and Fishery" (from 0.53 in 2010 to 0.65 in 2013) and "Electricity, Gas and Water Supply" (from 0.20 to 0.45), reflecting the decline in production capabilities or sudden rise in demand. Those of "Construction" and "Public Administration" also increased just after the disaster and then decreased. ${ }^{15}$ In the other sections, they have decreased or are stable. (Recent decreases, such as in "Transportation" sector, could be partially due to the strong reconstruction demand in the surrounding prefectures.)

\subsection{Effectiveness of a demand increase}

As Miyazawa (2005) describes, the sum of the column elements of the inverse matrix indicates the effect of an increase in final demand in the corresponding sector on the entire economy. ${ }^{16}$ In the case of this study, the inverse matrices are different for intraregional final demand and inter-regional final demand (i.e., export). Using Eq. 2.2 in Sect. 2, the former is $\left[I-\left(T^{r s}-\bar{M} T^{s s}\right) A\right]^{-1}\left(T^{r s}-\bar{M} T^{s s}\right)$ and the latter is $\left[I-\left(T^{r s}-\bar{M} T^{s s}\right) A\right]^{-1}$. In this subsection, the latter, the simpler one, is used for comparison among sectors as well as regions.

Figure 4 indicates the difference among regions. The effects have increased in most regions. The rates of increase have been relatively higher in North, Middle, South, and Soso. Rates typically increase when the demand for domestic goods (inputs or final products) recovers or rises. Taking into account the discussion from the previous section, the increase in South is thought to be related to growth in the manufacturing sector and its structural change. The increases in North and Middle could be due to a change in the service industries. The result given for Soso is likely due to the inter-regional nature of the electricity industry and its suspension. Higher increases in the regions severely affected by the disaster suggest that direct aid to those regions may benefit the entire prefecture.

Figures 5 and 6 show the effects (by sector) in North and Soso. In general, the values are higher for mining and transportation but lower for real estate. Real estate has no import by definition but uses little input so the overall effect is small. Figure 5 , the case of North, represents typical movements across all regions. As time passes, the effects gradually increase. Figure 6 shows the effects in Soso, the region most affected by the

\footnotetext{
${ }^{15}$ Usually, the imports of Construction and Public Administration sectors are set to be zero by definition. However, this study allows them to be positive as emergency supplies have been made.

16 This index is sometimes called "power of dispersion" when it is normalized (by dividing by the average) as has been suggested by Rasmussen (1956). Because its magnitude is also important, this study does not normalize and use the raw value.
} 


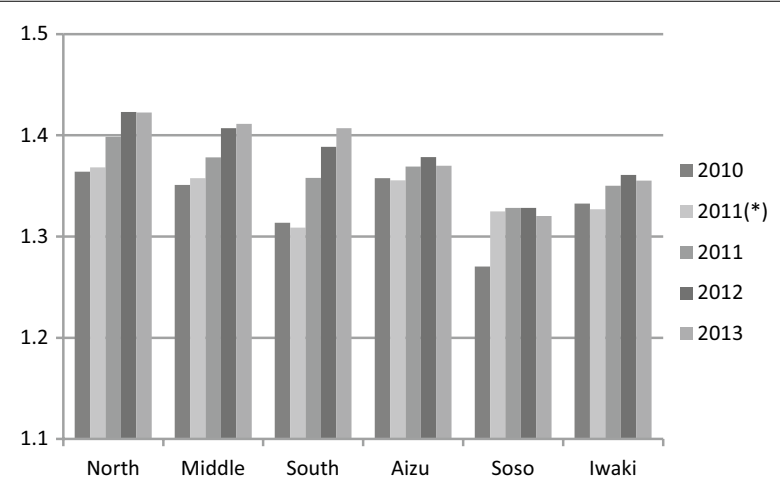

Fig. 4 Changes in the sums of the column elements of the inverse matrix (all sectors, simple averages)

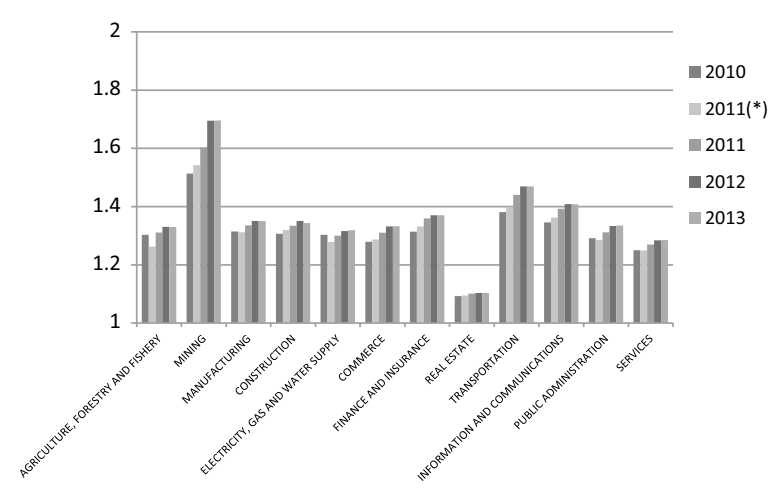

Fig. 5 Changes in the sums of the column elements of the inverse matrix (north)

disaster. In contrast to most of the other areas, the effects of the disaster have been decreasing over the last 2 years in stark contrast to their initial rise. It seems that the hollowing out of the region is reducing the effectiveness of a demand increase.

One should also note that there are some policy tools to aid recovery in areas such as public works, income subsidy (or tax cuts) and direct assistance to the agriculture, manufacturing, and utility (electricity and other) sectors. A public work (flow effect) mostly induces demand for construction and household consumption does the same for commerce, real estate, and services.

While the effects are converging, it can be demonstrated that the effect of income subsidy (commerce, real estate, and services) is still relatively lower in Soso.

\subsection{Sensitivity to economic recovery}

In contrast to the values shown in the previous subsection, the sum of the row elements of the inverse matrix measures the effect of increases in final demand (export) in all sectors of the economy for each sector (within a region). ${ }^{17}$ Figure 7 indicates difference among regions.

\footnotetext{
${ }^{17}$ Similarly to Sect. 4.2, this index is sometimes called "sensitivity of dispersion" or "production inducement coefficient" when it is normalized.
} 


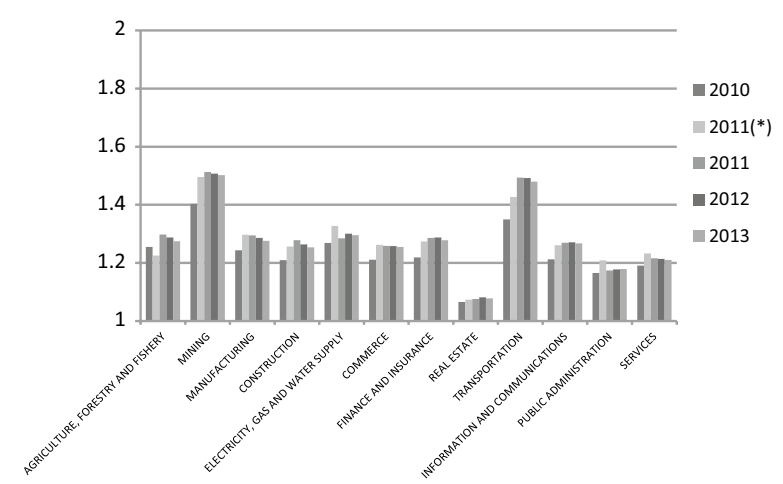

Fig. 6 Changes in the sums of the column elements of the inverse matrix (SoSo)

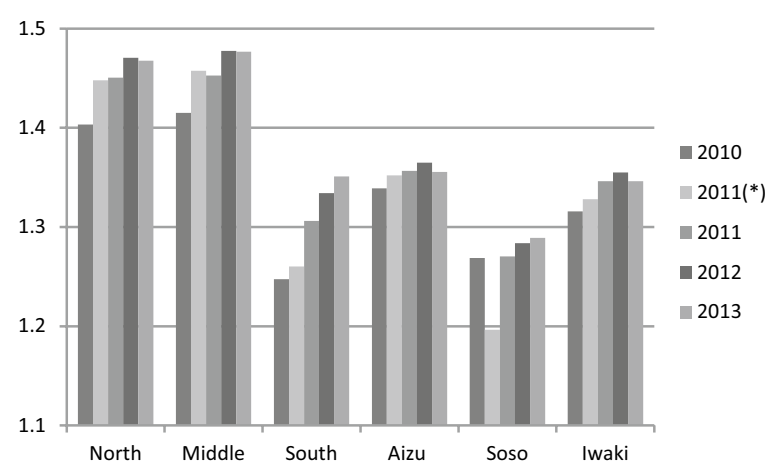

Fig. 7 Changes in the sums of the row elements of the inverse matrix (all sectors, weighted averages)

In general, the relative magnitude of values depends on those of intra-prefectural demands. The ones for South, Soso, and Iwaki were previously smaller. (Please note that these have border regions with closer links to neighboring prefectures.) Furthermore, the values for Soso remain static, while the others are increasing. That is, the people in Soso have benefitted less from the recovery of the entire economy or increases in exports.

Detailed investigation into the values for the various sectors indicate that the figures for sectors such as "Finance and Insurance," "Transportation," and "Services," which are largely dependent on regional induced demands, have strongly benefited from an increase in final demand. The effects on "Agriculture, Forestry and Fishery," "Mining," "Real Estate," and "Construction" are small, mostly because of their independence from other regional businesses.

In Soso, the values for "Agriculture, Forestry and Fishery" and "Electricity, Gas and Water Supply" declined sharply after the disaster (from 1.21 in 2010 to 1.02 in 2011 and from 2.07 to 1.65 during the same period, respectively), and have not yet recovered. If compensation had not been forthcoming, people within these businesses areas would have received little benefit from reconstruction. 


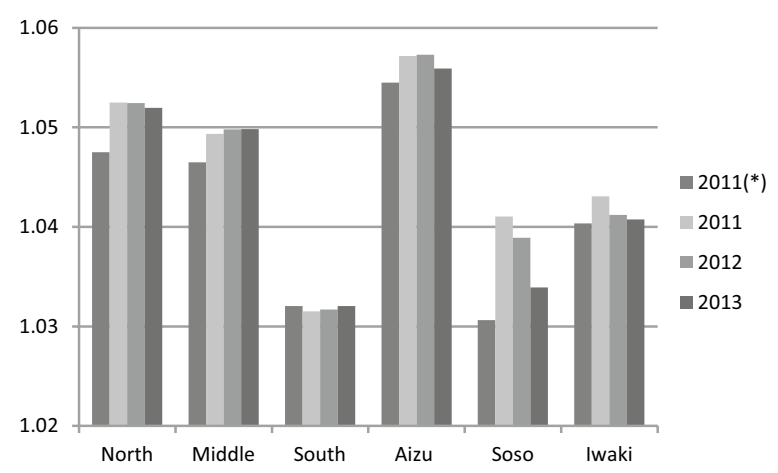

Fig. 8 The effects of $10 \%$ increases in all regional final demands

\subsection{The effects of $10 \%$ increases in regional final demands}

While interpretation of the effects illustrated in Sect. 4.2 is somewhat straightforward, validity of those in Sect. 4.3 is generally in question because these only evaluate the outcomes when final demands (exports) increase by one unit in all sectors and all regions (c.f. Miyazawa (2005)). Moreover, as far as reconstruction demand is concerned, regional final demand, not export, may well be the driving force of the economic recovery. This subsection deals with a more realistic case, in which regional final demands increase proportionally. ${ }^{18}$ Please note that regional final demands include "leaks," or imports from other regions or prefectures so that the effects are known to be to be smaller than they are in the case of exports.

Suppose final demands increase by $10 \%$ in all sectors of all regions. ${ }^{19}$ By recalculating using Eq. (2.9) from Sect. 2, new output values can be calculated. Figure 8 indicates the changes in total outputs of the six regions. The effects are larger in North, Middle, and Aizu. Although they have increased in most regions since the disaster, conspicuously for 2013, they seem to be returning their original levels.

As has been previously noted, the difference from Sect. 4.3 is due to the facts that (1) final demands are raised proportionally so that the original shares of the sectors become significant and (2) regional final demands are changed instead of external demands (exports). The changes in the values of South and Soso are entirely different from those in Fig. 7 because of their dependency on export industries. These movements may well indicate the end of the domestic reconstruction boom; further observations will be necessary for a definitive conclusion.

Figures 9 and 10 show details of the effects in North and Soso, respectively. First of all, the relative values for "Construction" and "Real Estate" are, because of their domestic propensity, completely different to the case in Sect. 4.3. The figures for the tertiary industry, which is mostly domestic, are also relatively higher. The values are by contrast

\footnotetext{
${ }^{18}$ One can consider an even more realistic case in which the regional final demands increase according to specific rule (e.g., one consistent with an actual policy). However, because of the up-to-date nature of this study, it is difficult to identify the policy most likely to be executed. Instead, this study offers a more general analysis.

19 For more realistic analyses, it is possible to assume that those changes are at purchasers' values. Then, those changes are converted to producers' values taking into account the contributions of commerce and transportation sectors. However, the only reliable data on the margins of those sectors are released at national level and not expected to represent the particular situation after the disaster. Therefore, this study simply assumes the changes are at producers' values.
} 


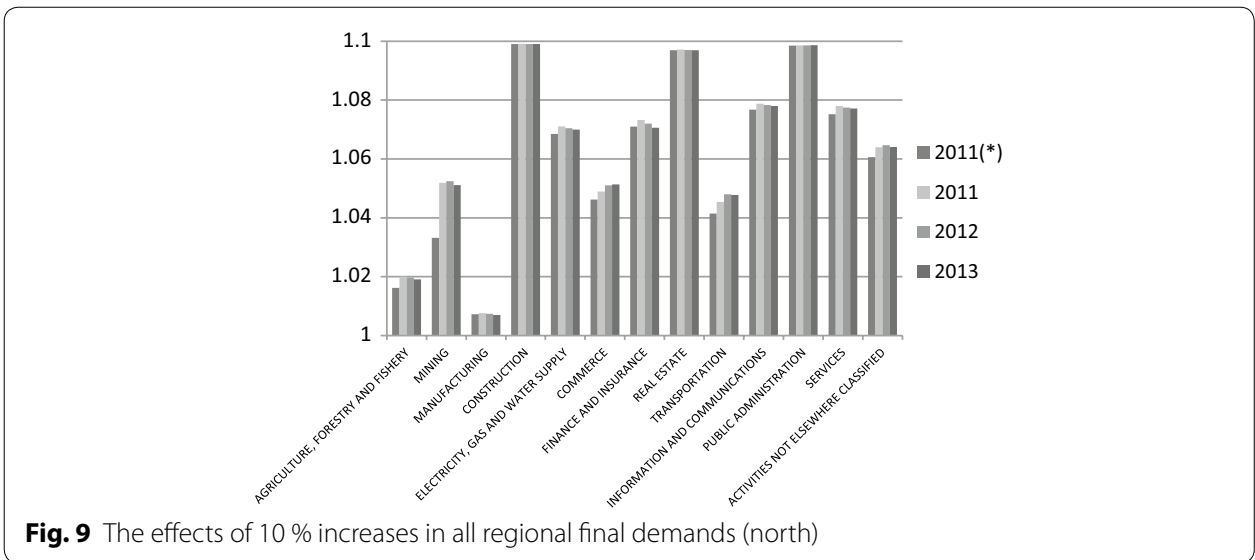

Fig. 9 The effects of $10 \%$ increases in all regional final demands (north)

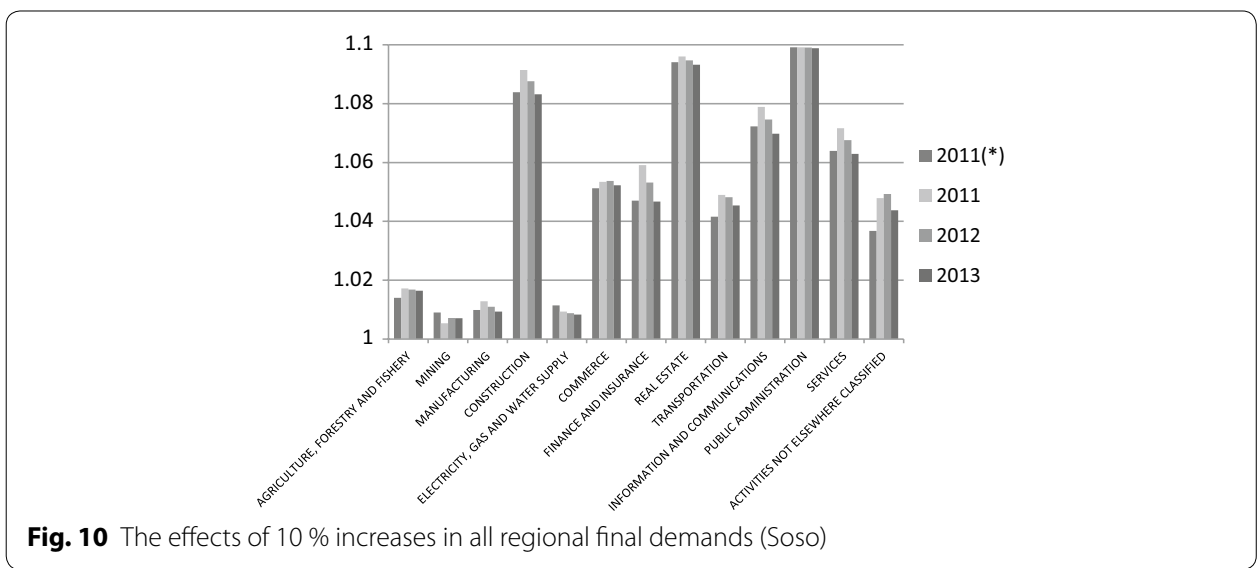

small in the sectors of "Agriculture, Forestry and Fishery" and "Manufacturing" for these regions.

North represents a typical case in which movements demonstrate an inverted U-shape in all the major sectors. In Soso, the values have been recently decreasing in many sectors. This is even more obvious when considering the "Electricity, Gas and Water Supply" sector there. Even though reconstruction is progressing throughout the prefecture, the most devastated region, Soso, can still be considered to be losing its ability to receive benefits.

\section{Concluding remarks}

This study has characterized the changes in trade structures for a number of regions in the Fukushima prefecture of Japan, as a result of the 2011 Tohoku earthquake, tsunami, and the resulting incident at the Fukushima Daiichi Nuclear Power Station.

In Sect. 3, outputs for the 3 years following the disaster have been estimated for each sector and region using actual data. Among these estimates, declines in "Agriculture, Forestry and Fishery" and "Electricity, Gas and Water Supply" are noticeably marked in the regions most affected by the disaster but output for "Construction," in contrast, has risen. "Manufacturing" has increased in South while decreased at first and has not as 
yet returned to the original level in other regions. In other sectors, recoveries have been observed in most instances. In Sect. 4, sensitivity analyses, which quantify the changes in backward-linkage effects, have been performed. The rate of import, which directly reduces the ripple effect, has decreased or is now considered more stable in many sections and regions. In general, as reconstruction progresses, the trade structure is gradually returning to its original state and stabilizing. However, the import rates are still higher in some sectors or regions (e.g., "Agriculture, Forestry and Fishery," "Electricity, Gas and Water Supply," or "Public Administration" in coastal regions).

According to Reconstruction Promotion Committee (2012) and Reconstruction Agency (2015), current public support can be largely classified into (1) (direct) support for those affected by the disaster, (2) reconstruction (rebuilding the facilities and others), (3) support for industry and employment promotion, and (4) support in coping with the nuclear disaster. The budget for (2), reconstruction, accounts for the largest part in the national special account and 7581 billion yen has been allocated to fund the relief effort by the end of the 2014 fiscal year. For (1), (3), and (4), the corresponding amounts are 1813 billion yen, 3858 billion yen, and 2753 billion yen, respectively. Note that, (4) is considered to have been spent mainly in Fukushima prefecture, while (1), (2), and (3) are used in the entire region. ${ }^{20}$

The first problem with this public support is, as many researchers have already pointed out, its low execution rates. The budget execution rate for (2), reconstruction, is merely $71.7 \%$ and the remainder unused (either canceled or carried over). The rates for (1) and (4) are also not so high ( $84.2 \%$ and $74.5 \%$, respectively) while the figure for (3) is $92.1 \%$. The results of Sect. 4.2 indicate the effect (multiplier) of an increased demand on the prefectural economy exceeds 1.2 in most sectors. In particular, that of "Construction" is not as low and by contrast and at least higher than "Services." That is, if the budget is fully executed (e.g., any public works are conducted), it has a considerable impact on the economy. There is no doubt the "remaining budget" should spent wisely to maximize recovery. According to the results of Sect. 4.2, the effect has increased in most regions over 3 years. The rates of increase have been relatively higher in North, Middle, South, and Soso. Higher increases in the regions severely affected by the disaster may justify prompt support for those regions.

Second, because there is a huge disparity among sectors as well as regions in receiving recovery benefits, systematic support is necessary for disadvantaged industries and people. Currently, according to Reconstruction Agency (2015), even the sum of the amount of direct support for those affected and support for industry and employment promotion is less than that of reconstruction (rebuilding the facilities and other). The amounts are considered to be insufficient to eliminate the difference in the recovery benefits. In particular, considering the analyses in Sects. 4.3 and 4.4, one should note that Soso (the most effected region) and South are expected to have difficulties in receiving the benefit. And, in general, primary and secondary industries have not benefitted from the recovery to any great extent and the situation has improved very little since the disaster.

Finally, support should be arranged strategically taking into account conditions 3 years after the disaster. 1689 billion yen (61 \%) of the 2753 billion yen, which has been

${ }^{20}$ The indicated figures are the ones for the entire nation. So far, the author has not obtained reliable figures solely for Fukushima prefecture. 
disbursed to cope with the nuclear disaster, has been used for "decontamination." Also, it can be seen that a large part of the budget has been used unsuccessfully, failing to repair all the damage resulting from the disaster. Although many sectors and regions have already recovered, noting the results of Sects. 4.3 and 4.4, it can be seen there are several sectors and regions that have been displaying the symptoms of economic difficulty for years. The policymakers now need to decide whether to encourage firms or people to move to more promising locations or to continue restoration of the damaged ones.

Future extensions of this study may include (1) improvement of the input-output tables, particularly the estimates of the trades among regions, (2) more realistic policy analysis, such as altering the final demand data according to actual policy plans, and (3) careful treatment of conditions not represented by currently available data, for example, the situation and behavior of the evacuees, psychological aspects, the effects of aid or compensation income on the population, distorted housing market, relocation of the industries and public services, changes in the transportation system, decommission and restoration process of power plants, progress in management of radioactive contamination, and investment in disaster prevention.

\section{Acknowledgements}

This paper has benefited from the comments of Dr. John Winters and other attendants of 59th Annual North American Meetings of the Regional Science Association International (Ottawa, Canada) and Dr. Jan Oosterhaven, Dr. Yoshio Kajitani and other attendants of the 21 st International Input-output Conference (Kitakyushu, Japan.) I would also like to thank anonymous referees of the Journal, Mr. Andrew Cousins, who provided language support and Mr. Akira Kanno, who supported me in many ways as the coauthor of the previous paper.

\section{Competing interests}

The author declares that he has no competing interests.

Received: 29 December 2014 Accepted: 20 December 2015

Published online: 02 January 2016

\section{References}

Asari I, Doi E (2008) On the method to analyze the inter-regional economic differences with inter-regional input-output tables. Shizuoka Daigaku Keizai Kenkyu. 12(4):19-36 (in Japanese)

Cabinet Office (2012) Annual Report on the Japanese Economy and Public Finance (in Japanese)

Cochrane HC (1974) Predicting the economic impacts of earthquakes. Natural hazard research working paper no. 25 Institute of Behavioral Science, University of Colorado, pp 1-41

Chujo J, Fujii T, Ishikawa Y (2013) Study on Business Interruption of the Manufacturing Industry by the Great East Japan Earthquake. Infrastruct Plan Rev 69(5):173-179 (in Japanese)

Dietzenbacher E, van der Linden J, Steenge A (1993) The Regional extraction method: EC input-output comparisons. Econ Syst Res 5:185-206

Fukushima Prefecture, Planning and Coordination Department (2010) Heisei 17 (2005) Input-Output Tables of Fukushima Prefecture (in Japanese)

Fukushima Prefecture, Planning and Coordination Department (2011) Heisei 17 (2005) Input-Output tables for living spheres of Fukushima Prefecture, Excellent Graphical Report on Regional Analysis (Anarize Fukushima), No.19. (in Japanese)

Fukushima Prefecture, Agriculture, Forestry and Fishery Department (2013) Fukushima-ken Norinsuisangyo no Genjo (The Present Conditions of Agriculture, Forestry and Fishery of Fukushima Prefecture) (in Japanese)

Hayashiyama Y, Nakajima K, Sakamoto N, Abe M (2014) Measurement of regional redistributive effects of investment for reconstruction from the Great East Japan Earthquake. RIETI Discussion Paper Series, 14-J-004 (in Japanese)

Ihara R, Nakamura R, Morita M (2013) Impacts of the Great East Japan Earthquake on Regional Potentials and Labor Distribution in Miyagi Prefecture, RIETI Discussion Paper Series, 13-J-053 (in Japanese)

Miller RE, Lahr ML (2001) A taxonomy of extractions. In: Lahr ML, Miller RE (eds) Regional science perspectives in economic analysis. Elsevier, Amsterdam, pp 407-441

Miyagi T, Ishikawa Y, Shimizu M, Yuri S (2003) Construction of interregional input-output table at prefecture level using intra-regional input-output table. Infrastruct Plan Rev 20(1):87-95 (in Japanese)

Miyazawa K (2005) Sangyorenkanbunseki Nyumon (Introduction to Input-Output Analysis), Nikkei (in Japanese)

Nakano S, Nishimura K (2007) Estimation of multiregional transactions in partitioning regional input-output table. Innov I-O Technique, PAPAIOS 15(3):44-53 (in Japanese) 
Nozaki M (2013) The Analytical Survey and Empirical Study of Economic Impact of the Natural Disasters: Input-Output Framework, Annual Report, Hirosaki University Graduate School Regional Studies, 9, pp 23-39 (in Japanese)

Nozaki M (2015) The impact of production and infrastructure shocks: a non-linear input-output programming approach, tested on a hypothetical economy, Annual Report, Hirosaki University Graduate School Regional Studies, 11, pp 23-32 (in Japanese)

Okamoto N, Sano T, Inomata S (2005) Estimation technique of international input-output model by non-survey method, IDE Discussion Paper, No. 28

Okuyama Y, Hewings GJD, Sonis M (2004) Measuring the economic impacts of disasters: interregional input-output analysis using the sequential interindustry model. In Okuyama Y, Chang S (eds.). Modeling Spatial and Economic Impacts of Disasters, Springer, pp 77-101

Rasmussen PN (1956) Studies in inter-sectoral relations. Amsterdam, North-Holland

Reconstruction Agency (2015), Hukkokanrenyosan no Shikkojokyo (Situation of Budget Execution Related to Recovery), Press Release (in Japanese)

Reconstruction Promotion Committee (2012), FY2012 Interim Report

Regional Industry Restoration Research Project, Graduate School of Economics and Management, Tohoku University (2014), Reports of the Regional Industry Restoration Research Project III (in Japanese)

Rose A, Stephanie J, Chang E, Szczesniak P, Lim D (1997) The regional economic impact of an earthquake: direct and Indirect effects of electricity lifeline disruptions. J Regional Sci 37:437-458

Strassert G (1968) "Zur Bestimmung Strategischer Sektoren mit Hilfe von Input-Output Modellen," Jahrbücher für Nationalökonomie und Statistik, vol. 182, pp. 211-215

Takahashi A, Ando A, Mun S (1997) Estimation of the economic damages caused by the Hanshin-Awaji great earthquake. Infrastruct Plan Rev 14:149-156 (in Japanese)

Tokunaga SM, Okiyama, Akune Y (2013) Analyses of disrupted supply chains by the Great East Japan Earthquake and reconstruction of the disaster-affected region by the cluster of the automotive industry: Utilizing the regional CGE model, Discussion Papers 13-J-068, Research Institute of Economy, Trade and Industry (in Japanese)

Tsuchiya S, Tatano H, Okada N (2005) Measuring economic impacts from the Niigataken-Chuetsu earthquake. Kyoto University Research Information Repository, no. 48B, pp 117-124 (in Japanese)

Van Dijk J, Oosterhaven J (1985) Regional impacts of migrants' expenditures: an input-output/vacancy-chain approach. In: Batey PWJ, Madden M. Integrated analysis of regional systems. London Papers in Regional Science 15, London: Pion, pp 122-47

Yamano N, Kajitani Y, Shumuta Y (2007) Modeling the regional economic loss of natural disasters: the search for economic hotspots. Econ Syst Res 19(2):163-181

Yonemoto K (2012) Migration in and around Fukushima, Japan, An Interregional Input-Output and Spatial Analysis, a presented paper in the 59th Annual North American Meetings of the Regional Science Association International (Ottawa, Canada) (in Japanese)

Yonemoto K (2013), Input-output and trade structures of the regions of Fukushima, Japan: Before and After the Disaster, a presented paper in the 21st International Input-output Conference of International Input-output Association (Kitakyushu, Japan) (in Japanese)

Yonemoto K, Kanno A (2011) Regional input-output analysis of the effect of 2011 Tohoku Earthquake on the Coastal Regions in Fukushima, a presented paper in the 22th Conference of Pan Pacific Association of Input-Output Studies (PAPAIOS) (in Japanese)

Yonemoto K, Kanno A (2012) Input-output and trade structure of the coastal regions of fukushima: the effects of 2011 Tohoku earthquake and the nuclear accident. Innov I-O Techn PAPAIOS 20(3):11-23 (in Japanese)

\section{Submit your manuscript to a SpringerOpen ${ }^{\circ}$ journal and benefit from:}

- Convenient online submission

Rigorous peer review

- Immediate publication on acceptance

- Open access: articles freely available online

- High visibility within the field

- Retaining the copyright to your article

Submit your next manuscript at $\boldsymbol{\nabla}$ springeropen.com 